\title{
PROPOSTA PARA PROCEDIMENTOS DE VISTORIA DE PROJETOS PRODUTOR DE ÁGUA: BACIA HIDROGRÁFICA DO RIO CAMBORIÚ - SC, BRASIL
}

\author{
SANTOS, P.H. ${ }^{1} \&$ SCHWINGEL, P.R. ${ }^{1 *}$ \\ 1Escola do Mar, Ciência e Tecnologia, Universidade do Vale do Itajaí - UNIVALI \\ *Corresponding author: schwingel@univali.br
}

\begin{abstract}
Santos, P.H. ${ }^{1}$ \& Schwingel, P.R. ${ }^{*}$ (2017). Proposta para procedimentos de vistoria de Projetos Produtor de Água: Bacia Hidrográfica do Rio Camboriú - SC, Brasil . Braz. J. Aquat. Sci. Technol. 21(1). elSSN $1983-9057$. DOI: $12.367 /$ bjast.v21n1. The conservation of water is a subject that has worried the human being, assuming a vital character in the present time due to the scarcity of the water resource. The Water Producer Program (PPA) in Brazil is an initiative of the National Water Agency (ANA), created with the objective of reducing erosion and silting of water bodies in rural areas. The Water Producer Project (PA), adopting the Payment for Environmental Services (PSA), was created for the Camboriú River Basin (SC) in 2013. Voluntary adhesion to the project provides, through contracts, the protection of riparian forests and springs covered with native vegetation, protection of areas with native vegetation cover, restoration of degraded areas inside and outside riparian forests and springs. The financial benefits are paid to contractors after positive opinion of the surveys. In this way, procedures are necessary to ensure the technical credibility of the surveys. After analyzing the PA project in the Camboriú River Basin, the present study proposes: flow chart for surveys and reports; check list; photographic register; training and documentation required for surveys. The proposal certifies a quality standard for the PPAs, guaranteeing greater credibility and effectiveness of the projects and enabling their replication in Brazil and abroad. As a result, this article presents in a systematized way a proposal for the inspection procedure for Water Producers projects.
\end{abstract}

Key words: Water producer, check list, survey manual

\section{INTRODUÇÃO}

A Bacia Hidrográfica do Rio Camboriú (BHRC) está localizada na região litorânea centro-norte do Estado de Santa Catarina, entre os municípios de Camboriú, a montante, e Balneário Camboriú, a jusante (Antunes et al., 2007). A área da BHRC tem aproximadamente $200 \mathrm{~km}^{2}$, sendo formada pelos rios Gavião, Braço. Ribeirão dos Macacos, Canoas, Pequeno e Peroba (Dacol, 2011). Segundo Silva (2015), a BHRC apresenta vários problemas ambientais que dificultam o gerenciamento dos recursos hídricos, e.g. uso e ocupação inadequada do solo e subtração da mata ciliar.

Em 2013 a Empresa Municipal de Saneamento de Balneário Camboriú (EMASA) criou o projeto Produtor de Água (PA), que tem como principal meta o aumento da quantidade e qualidade da água na BHRC. Através de contratos firmados com os proprietários rurais, o PA realiza Pagamentos por Serviços Ambientais (PSA) como incentivo financeiro e técnico aos contratados (Antunes, 2014). PSA é uma das políticas públicas que está sendo utilizada como ferramenta essencial que visa incentivar a conservação e restauração de florestas e a adoção de sistema produtos mais sustentáveis em propriedades rurais. (Pagiola. et al, 2013).

Como exemplo de serviços ambientais pode ser destacado, o plantio de árvores nativas que reduz sedi- mentos, aumenta a infiltração de água no solo, fornece habitat aos animais e outros (Santos, 2009). Para que os pagamentos sejam executados é necessária uma vistoria técnica da equipe formada por membros titulares do Grupo Gestor do PA. A vistoria tem o objetivo certificar que as ações de conservação e restauração previstas nos Projeto Individual de Propriedade (PIP) estão sendo executadas em conformidade com os contratos. Desta forma, o objetivo do presente trabalho é estabelecer orientações para as vistorias de projetos Produtor de Água, incluindo checklist para vistorias e relatórios, assegurando um padrão de qualidade na gestão de cada projeto.

Fluxograma para vistorias e relatórios do projeto produtor de água

As atribuições do Grupo Gestor na fiscalização do PA da BHRC foram estabelecidas conforme documento "Edital de chamamento 2016 da EMASA". Na décima cláusula, sobre a fiscalização consta que a fiscalização e gestão diretas do presente termo ficarão a cargo da Concedente, bem como as verificações e certificações nas propriedades é de responsabilidade da Equipe de Vistoria do Projeto, designada pelo Grupo Gestor (GG). As vistorias são semestrais e após as mesmas, deve ser elaborado relatório fundamentado atestando o cumprimento ou descumprimento das ações e condições definidas. De posse do relatório 
de vistoria, o Grupo Gestor avaliará o atendimento às cláusulas deste instrumento e emitirá parecer para a Concedente (EMASA, 2016).

Assim, o documento "Edital de chamamento 2016 da EMASA" estabelece de forma clara os critérios para a fiscalização das vistorias e elaboração dos relatórios. Estes procedimentos foram sintetizados no fluxograma apresentado na Figura 1.

\section{Checklist da vistoria}

Segundo Pancieri et al. (2013), o checklist é um instrumento desenvolvido por especialista composto por três etapas: identificação, confirmação e registro, sendo de fácil e rápida aplicação. Desta forma, esse instrumento pode ser usado para verificar se os serviços ambientais contratados estão sendo executados pelos proprietários do PA, i.e. proteção de matas ciliares e nascentes cobertas com vegetação nativa; proteção de áreas com cobertura vegetal nativa; restauração de áreas degradadas em matas ciliares e nascentes; e restauração de áreas degradadas fora de matas ciliares ou nascentes (Figura 2). O checklist (frente e verso) inclui também dados do proprietário, da propriedade e espaços para registro de observações e assinaturas dos membros da Equipe de Vistoria e Proprietário.

\section{Registro fotográfico}

O registro da vistoria, usando a fotografia, é um meio para obter informação e recordações. Portanto, durante as vistorias do PA, o registro fotográfico é importante para comprovar a mesma e verificar o checklist a posteriori (Figura 3).

\section{Treinamento da equipe de vistoria}

A tarefa de formação de recursos humanos para vistorias deve incluir trabalho teórico, excursões e coleta de dados em campo (Tundisi \& Tundisi, 2008). Para tanto, é necessário treinamento da equipe responsável por essa atividade. A falta de capacitação compromete a qualidade do serviço e a credibilidade dos projetos Produtor de Água. O Grupo Gestor, juntamente com a Concedente, deverá treinar a equipe de vistoriadores, que é composta por instituições parceiras do projeto Produtor de Água (PA), garantindo que os responsáveis estejam aptos para executar as vistorias e elaborar os relatórios.

\section{Documentação do produtor de água}

Os documentos do Projeto Produtor de Água consistem em fontes de informações, sendo importante o livre acesso a eles, especialmente pelo Grupo Gestor, garantindo transparência e uma melhor gestão dos projetos. Para a realização das vistorias são necessários documentos que estão em posse da Concedente. Este fato pode dificultar a realização da mesma, bem como a elaboração de relatório. Por este motivo, o Grupo Gestor deve ter livre acesso, tanto aos contratos entre proprietários rurais e a Concedente, quanto ao Projeto Individual de Propriedade.

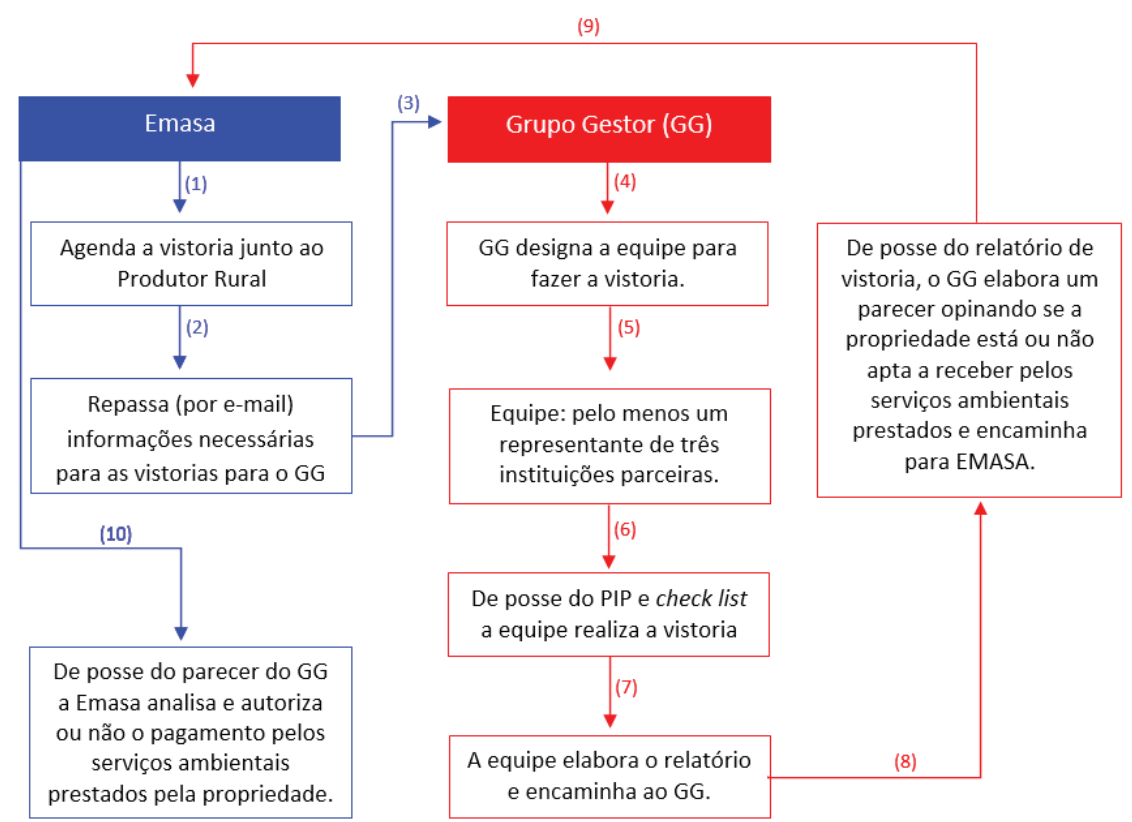

Figura 1 - Fluxograma para vistorias do Projeto de Ảgua da Bacia Hidrográfica do Rio Camboriú (SC). 


\begin{tabular}{|c|c|c|c|c|c|c|}
\hline \multicolumn{7}{|c|}{ Check list da Vistoria do Projeto Produtor de Agua da Bacia Hidrográfica do Rio Camboriú } \\
\hline \multicolumn{3}{|c|}{ Nome do proprietário e assinatura: } & \multicolumn{4}{|c|}{ Data da vistoria } \\
\hline \multicolumn{3}{|c|}{ Equipe de vistoria: } & \multicolumn{4}{|c|}{ C.P.PR } \\
\hline \multicolumn{7}{|c|}{ Aspectos a serem analisados pela equipe de vistoria: } \\
\hline \multicolumn{7}{|c|}{ Proteção de mata ciliar e nascentes cobertas com vegetaç̃o nativa } \\
\hline Item & Descriçấo & $\mathrm{s}$ & $\mathrm{N}$ & $\mathrm{P}$ & NO : & $\mathrm{NP}$ \\
\hline 01 & A mata ciliar encontra-se conservada com vegetação nativa? & 口 & 口. & 口: & 口 & 口 \\
\hline 02 & Há indícios de desmatamento na área da mata ciliar? & $\square$ & $\square$ & 口 & 口 & ㅁ \\
\hline 03 & Observam-se pontos de erosão ao longo da mata ciliar? & ㅁ & ㅁ. & 口 & ㅁ. & ㅁ \\
\hline 04 & A área de proteção está sendo usada como pastagem? & ㅁ & ㅁ. & ㅁ. & ㅁ. & ㅁ \\
\hline 05 & As nascentes contam com a proteção da vegetaçăo nativa? & 口 & $\square$ & 口: & ㅁ. & 口 \\
\hline 06 & Em torno da nascente existe(m) área(s) sem vegetação nativa? & 口 & ㅁ. & 口. & 口 & 口 \\
\hline 07 & Observam-se pontos de erosão em torno da nascente? & ㅁ & ㅁ. & 口. & 口. & ㅁ \\
\hline 08 & A nascente e mata ciliar encontram-se protegidas com cerca? & 口 & 口. & 口: & 口: & 口 \\
\hline \multicolumn{7}{|c|}{ Proteção em áreas de reserva florestal } \\
\hline Item & Descriçẫo & s & $\mathrm{N}$ & $\mathrm{P}$ & NO & $\mathrm{NP}$ \\
\hline 01 & Existe solo exposto, sem cobertura de vegetaçâo? & 口 & 口 & 口: & 口: & 口 \\
\hline 02 & Há indícios de desmatamento na área de proteçâo? & 口 & 口 & 口. & 口. & 口 \\
\hline 03 & A área de proteção está sendo usada como pastagem? & ㅁ & 미 & 口 & 口 & ㅁ \\
\hline 04 & Observam-se pontos de erosão na área protegida? & 口 & 口 & 口 & 口: & 口 \\
\hline 05 & Foi observada a presença de animais silvestres na área protegida? & ㅁ & ㅁ. & 口. & 口. & ㅁ \\
\hline 06 & A área de proteção está sendo usada para fins recreativos? & 口 & ㅁ. & 口 & 口 & 口 \\
\hline 07 & O proprietário tem cuidado da área protegida? & 만 & 미 & 口 & 口 & 므 \\
\hline \multicolumn{7}{|c|}{ Recuperação de áreas degradadas em mata ciliar e nascente(s) } \\
\hline Item & Descriçấo & $\mathrm{s}$ & $\mathrm{N}$ & $\mathrm{P}$ & NO : & $\mathrm{NP}$ \\
\hline 01 & As mudas plantadas estầ desenvolvendo-se naturalmente? & 口 & 口: & 口. & 口: & 口 \\
\hline 02 & A nascente encontra-se protegida com cerca e outros? & 口 & 口 & 口 & $\square$ & 口 \\
\hline 03 & A área de proteção está sendo usada com pastagem? & 口 & 口) & 口: & 口: & $\square$ \\
\hline 04 & Há necessidade de fazer replantio de mudas? & ㅁ & 口. & 口: & ㅁ. & ㅁ \\
\hline 05 & Está acontecendo a regeneração da área? & 口 & 口. & 口 & 口 & 口 \\
\hline 06 & Foi observada a presença de animais silvestres na área? & ㅁ & 미 & 口 & ㅁ. & ㅁ \\
\hline 07 & A área onde foram plantadas as mudas necessita de manutenção? & 口 & 口) & 口| & 口. & 口 \\
\hline 08 & O proprietário tem cuidado da área? & $\square$ & $\square$ & 口 & $\square$ & ㅁ \\
\hline \multicolumn{7}{|c|}{ Recuperação em áreas degradadas de reserva florestal } \\
\hline Item & Descriçãa & $\mathrm{s}$ & $\mathrm{N}$ & $\mathrm{P}$ & NO & $\mathrm{NP}$ \\
\hline 01 & As mudas plantadas estão desenvolvendo-se naturalmente? & 口 & 口) & 口) & 口: & 口 \\
\hline 02 & A área de proteção está sendo usada como pastagem? & 口 & 口: & 口. & 口. & 口 \\
\hline 03 & Há necessidade de fazer replantio de mudas? & 口 & $\square$ & 口 & 口) & 口 \\
\hline 04 & Foi observado indício da regeneração na área? & 口 & ㅁ & 口: & ㅁ. & 口 \\
\hline 05 & Foi observada a presença de animais silvestres na área? & 口 & 口: & 口. & 口. & 口 \\
\hline 06 & A área de recuperação está sendo usada para fins recreativos? & 口 & 口: & $\square$ & 口) & 口 \\
\hline 07 & A área onde foram plantadas as mudas necessita de manutenção? & 口 & 口. & 口: & 口: & 口 \\
\hline 08 & O proprietário tem cuidado da área? & 口 & 口: & 口: & 口: & 口 \\
\hline & $\begin{array}{l}\text { da: C. = Código Propriedade; } S=S \text { Sim; } \quad \mathrm{N}=\text { Não; } \quad \mathrm{P}= \\
\text { Aplica e NO = Năo Observado. }\end{array}$ & e & & & & \\
\hline
\end{tabular}

Figura 2 - Check list (frente) para vistorias do projeto Produtor de Água da Bacia Hidrográfica do Rio Camboriú-SC.

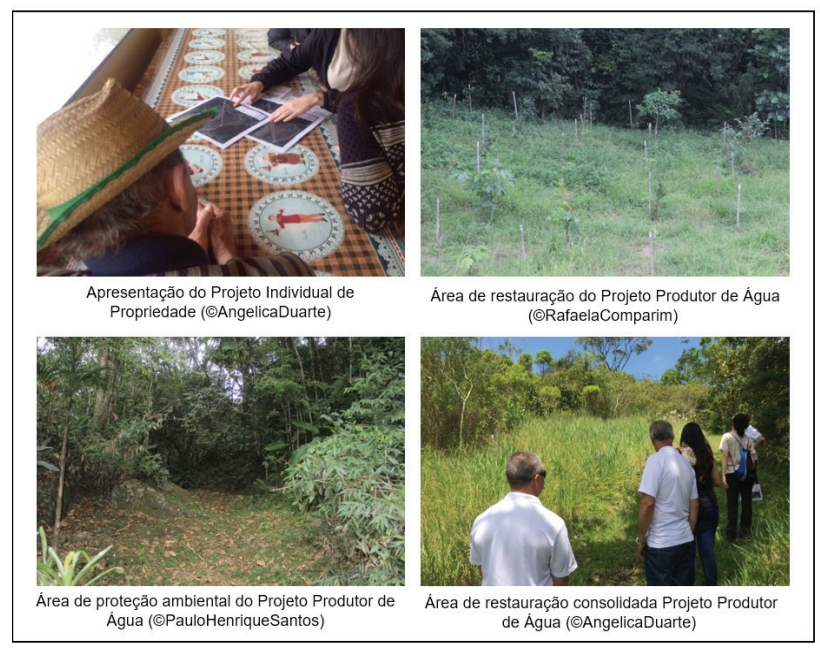

Figura 3 - Registros fotográficos de vistoria do Projeto Produtor de Água da Bacia Hidrográfica do Rio Camboriú-SC.

\section{CONCLUSÃO}

O aumento do número de projetos Produtores de Água no Brasil e em outros países resulta na necessidade de controle sistemático e documentado das vistorias, garantindo a eficácia, credibilidade e melhor gestão de programas de Pagamento por Serviços Ambientais associados a preservação e recuperação de mananciais hídricos.

\section{REFERÊNCIAS}

ANA - Agência Nacional de Águas. 2008. Programa Produtor de Água. Brasília. 23p.

ANA - Agência Nacional de Águas. 2012. Manual Operativo. Programa Produtor de Água. Brasília. $66 \mathrm{p}$.

Antunes, P.P. 2014. Pagamento por Serviços Ambientais: O projeto Produtor de Águas na Bacia Hidrográfica do Rio Camboriú como Instrumento de Conservação Ambiental no Município de Camboriú (SC). Tese de Doutorado. Universidade do Vale Itajaí. 162p.

Antunes, A.; Schwingel, P.R.; Burliga, A.L.M. \& Urban, S.R. 2007. Composição do fitoplâncton na bacia hidrográfica do rio Camboriú (SC Brasil) durante o verão de 2005. Braz. J. Aquat. Sci. Technol., v.11, n.2, p.33-43.

Dacol, K.C. 2011. Pagamento por Serviços Ambientais: Critérios de Valoração do Projeto Produtor de Água do Rio. Monografia. Centro de Ciências Exatas e Tecnologia- Pontifícia Universidade Católica do Paraná. 46p.

EMASA-Empresa Municipal de Água e Saneamento de Balneário Camboriú. 2016. Edital de Chamamento 01.2016. Produtor de Água.

MMA- Ministério do Meio Ambiente. 2011. Pagamentos por Serviços Ambientais na Mata Atlântica - lições aprendidas e desafios. Brasília, 272p.

Pagiola, S.; Glehn, H.C.V.;Taffarello, D. 2013. Experiências de pagamento por serviços ambientais no Brasil. Secretaria do Meio Ambiente de São Paulo. São Paulo.336p.

Pancieri, A. P; Santos, B. P; Avila, M. A. G.; Braga, E.M. 2013. Checklist de cirurgia segura: análise da segurança e comunicação das equipes de um hospital escola. Rev. Gaúcha. Enf., Rio Grande do Sul, v. 34, n. 1, p. 71-78.

Santos, D.G. 2009. Programa Produtor de Água. In: Bose, M. (Org) O pagamento por serviços ambientais: o mercado de carbono promove a inclusão social? Goiânia: Editora UCG, 386p.

Silva, D.D.P. 2015. Caracterização ambiental dos principais afluentes da Bacia Hidrográfica do Rio Camboriú (SC). Monografia de Graduação (Engenharia Ambiental), Universidade do Vale do Itajaí.

Tundisi, J.G.; Tundisi, T.M. 2008. Limnologia. São Paulo: Oficina de Textos.

Submetido: Março/18

Revisado: Maio/18 Aceito:Maio/18

Publicado: 15 de Julho/18 